\title{
Editorial
}

\section{Impact of Promotional Activities of Pharmaceutical Companies over Prescribing Practices of Health Professionals}

\author{
Received: February 4, 2019 Accepted: April 4, 2019 \\ doi: https://doi.org/10.3329/jemc.v9i2.41407
}

Physicians' prescribing practices are influenced by so many factors - level of knowledge, colleagues/ seniors, textbooks, journals, internet, conferences, media and last but not the least drug promotion. ${ }^{1}$ Among these factors the most vulnerable factor for errors, bias and influence is drug promotion. The World Health Organization defines drug promotion as all informational and persuasive activities by manufacturers and distributors, the effect of which is to influence the prescription, supply, purchase, or use of medicinal drugs. ${ }^{2}$ Nowadays, physicians are misinformed or misguided by the promotional activities of manufacturers merely for their financial gains. It is a known fact that pharmaceutical companies spend huge amount of money from drug promotion. They use different means of promotion like sale representatives, free samples, advertisements in media, and sponsorship of educational events and conferences. ${ }^{3}$ These promotional activities influence doctors, which give way for inappropriate prescribing and contribute to increased health care costs benefiting the patients. ${ }^{4}$ One study estimates that U.S. pharmaceutical industry spends almost twice as much on promotion as it does on research and development. ${ }^{5}$ In another study carried out in 2005 it was found that money spent on medicine promotion in United States was approximately $\$ 57$ billion. ${ }^{6}$ Different means of medicine promotions in United States are free samples (56\%), pharmaceutical sale representative 'detailing' physicians $(25 \%)$, direct to user advertising (12.5\%), detailing to hospitals (4\%) and journal ads $(2 \%){ }^{7} \mathrm{On}$ the other hand, there are so many benefits of this drug promotion. It mainly helps in rapid distribution of the scientific information/data gained from clinical trials to the entire health care professionals. But ideally, physicians' prescribing habits should be based on rational pharmacotherapy processes which include choosing appropriate drugs with desired dose and duration, among the various available options, which can be beneficial to both the patient and health care system. ${ }^{8}$ These pharmaceutical companies sometimes promote the drugs unethically by hiding their safety profiles, by exaggerated efficacy claims of 'me too drugs', irrational drug combinations and off label use. By doing so, they influence the doctors prescribing attitudes. Both doctors and pharmaceutical companies have to be blamed since the doctors also blindly overprescribe the drugs for minor financial benefits/ margin of the profits gained by selling these drugs. Sometimes doctors even demand incentives and their association threatens to stop prescribing the companies drugs that do not comply with their demands for sponsorship. There are numerous studies which tried to explore the irrationalities from only one angle, i.e., the pharmaceuticals drug promotional literature..$^{9-11}$

Health care professionals should always depend on the trusted source of information, since patient care is the prime goal of all the health care activities. In drug promotion, the pharmaceutical companies use one more important mode to directly influence the doctors, the medical representatives. These representatives attract health care professionals towards their products by giving gifts (ranging from pens/pads to expensive foreign tours/trips). Such activities are deep-rooted into our health care sector. To be involved in such activities is an offence in spite of knowing it to be unethical according to the medical code of conduct. ${ }^{5}$

There are so many irrationalities and unethical practices prevailing in the health care segment and the ultimate sufferer is the patient. Therefore, the health care professional should not depend on these promotional activities as the trusted source of drug. There are numerous scopes for new laws and regulations for identifying and penalizing these unethical practices. These include mandated disclosure by pharmaceutical companies of the expenditure incurred on drug promotion and disqualification of the product and penalty on the company for unethical drug promotional literature. No laws or regulations can ever change the scenario. It is one's own responsibilities, attitude and conscience that have to be altered and everyone should work as if the ultimate motto is patient safety and benefit rather than personal 
financial gains. By doing so, at each and every step of health care delivery, improvements can be achieved as a whole.

\section{Zaida Rahman}

\section{Professor}

Department of Pharmacology \& Therapeutics

Enam Medical College, Savar, Dhaka

Email: zaida.rahman53@gmail.com

\section{References}

1. Narendran R, Narendranathan M. Influence of pharmaceutical marketing on prescription practices of physicians. J Indian Med Assoc 2013; 111(1): 47-50.

2. World Health Organization. Ethical criteria for medicinal drug promotion. Geneva 13 May, 1988. p. 16. Available at: http://www.apps.who.int/ medicinedocs/documents/whozip08e/whozip08e.pdf. Accessed May 2018.

3. Who.int [internet]. Essential Medicines and Health Products Information Portal, A world health organization resource. Available at: http://www.who. int/medicinedocs/pdf/s8109e/s8109e.pdf. Accessed January 2019.

4. Cardarelli R, Licciardone JC, Taylor LG. A crosssectional evidence-based review of pharmaceutical promotional marketing brochures and their underlying studies: is what they tell us important and true? BMC Fam Pract 2006; 7: 13-18.

5. Dixit R, Shekhar C, Rajesh CS, Madhuri S, Mane A. Drug promotional activities as a source of medical information \& its influence on prescribing. Int J Pham Bio Sci 2014; 4(3): 113-119.

6. Sufrin CB, Ross JS. Pharmaceutical industry marketing: understanding its impact on women's health. Obstet Gynecol Surv 2008; 63(9): 585-596.

7. Barfett J, Lanting B, Lee J, Lee M, Ng V, Simkhovich P. Pharmaceutical marketing to medical students: the study perspective. McGill Journal of Medicine 2004; 8: 21-27.

8. Akici A, Oktay S. Rational pharmacotherapy and pharmacovigilance. Curr Drug Saf 2007; 2(1): 65-69.

9. Mali SN, Dudhgaonkar S, Bachewar NP. Evaluation of rationality of promotional drug literature using world health organization guidelines. Indian J Pharmacol 2010; 42(5): 267-272.

10. Roy N, Madhiwalla N, Pai SA. Drug promotional practices in Mumbai: a qualitative study. Indian Journal of Medical Ethics 2007; 1(4): 57-61.

11. Shankar P, Dubey A, Subish P. Critical evaluation of drug promotion using role-plays. Medical Education 2006; 40: 472. 